\title{
Improvements on Low Level Activity Gamma Measurements and X-ray Spectrometry at the CEA-MADERE Measurement Platform
}

\author{
Victoria Sergeyeva ${ }^{a}$, Christophe Domergue, Christophe Destouches, Jean Michel Girard, \\ Hervé Philibert, Jonathan Bonora, Nicolas Thiollay, and Abdallah Lyoussi \\ CEA, DEN, DER, Instrumentation Sensors and Dosimetry Laboratory, Cadarache, 13108 Saint \\ Paul-lez-Durance, France
}

\begin{abstract}
The CEA MADERE platform (Measurement Applied to DosimEtry in REactors) is a part of the Instrumentation Sensors and Dosimetry Laboratory (LDCI). This facility is dedicated to the specific activity measurements of solid and radioactive samples using Gamma and X-ray spectrometry. MADERE is a high-performance facility devoted to neutron dosimetry for experimental programs performed in CEA and for the irradiation surveillance programmes of PWR vessels. The MADERE platform is engaged in a continuous improvement process. Recently, two High Efficiency diodes have been integrated to the MADERE platform in order to manage the accurate low level activity measurements (few Bq per sample). This new equipment provides a good level of efficiency over the energy range from $60 \mathrm{keV}$ to $2 \mathrm{MeV}$. The background continuum is reduced due to the use of a Ultra Low Background (ULB) lead shielding. Relative and absolute $\mathrm{X}$-ray measurement techniques have been improved in order to facilitate absolute rhodium activity measurement $\left(\mathrm{Rh}^{103 \mathrm{~m}}\right)$ on solid samples. Additional efforts have been made to increase the accuracy of the relative niobium $\left(\mathrm{Nb}^{93 \mathrm{~m}}\right)$ activity measurement technique. The way of setting up an absolute measurement method for niobium is under investigation. After a presentation of the MADERE's measurement devices, this paper focuses on the technological options taken into account for the design of high efficiency measurement devices. Then, studies performed on X-ray measurement techniques are presented. Some details about the calculation of uncertainties and correction factors are also mentioned. Finally, future research and development axes are exposed.
\end{abstract}

\section{Introduction}

The main goal of the MADERE platform is the determination of the specific activity level of solid radioactive dosimeters. These dosimeters are activated by the irradiations in the CEA reactor mockups (EOLE, MINERVE, MASURCA), in Material Testing Reactors (OSIRIS, future JHR) and in PWR vessels. Irradiations in the PWR are part of the surveillance program related to the vessel embrittlement under irradiation. Reactor mock-ups and MTR reactors host dosimeters for the experimental programs

\footnotetext{
${ }^{a}$ Corresponding author: victoria.sergeyeva@cea.fr
}

This is an Open Access article distributed under the terms of the Creative Commons Attribution License 2.0, which permits unrestricted use, distribution, and reproduction in any medium, provided the original work is properly cited. 
Table 1. Main neutron dosimeters used by MADERE platform.

\begin{tabular}{|c|c|c|c|c|}
\hline \multicolumn{2}{|c|}{ Dosimeter } & Reaction & $\begin{array}{c}\text { Energy threshold } \\
(\mathbf{M e V})\end{array}$ & Half-life \\
\hline \multirow{4}{*}{} & $\mathrm{Fe}$ & $\mathrm{Fe}^{54}(\mathrm{n}, \mathrm{p}) \mathrm{Mn}^{54}$ & $\mathrm{E}>3$ & $312.13 \mathrm{~d}$ \\
\cline { 2 - 5 } & $\mathrm{Co}$ & $\mathrm{Co}^{59}(\mathrm{n}, \gamma) \mathrm{Co}^{60}$ & $\mathrm{Th}+\mathrm{epi}$ & $5.271 \mathrm{y}$ \\
\cline { 2 - 5 } & $\mathrm{Cu}$ & $\mathrm{Cu}^{63}(\mathrm{n}, \alpha) \mathrm{Co}^{60}$ & $\mathrm{E}>6$ & $5.271 \mathrm{y}$ \\
\cline { 2 - 5 } & $\mathrm{Ni}$ & $\mathrm{Ni}^{58}(\mathrm{n}, \mathrm{p}) \mathrm{Co}^{58}$ & $\mathrm{E}>2.7$ & $70.82 \mathrm{~d}$ \\
\cline { 2 - 5 } & $\mathrm{Au}$ & $\mathrm{Au}^{197}(\mathrm{n}, \gamma) \mathrm{Au}^{198}$ & $\mathrm{Th}+\mathrm{epi}$ & $2.6944 \mathrm{~d}$ \\
\cline { 2 - 5 } & $\mathrm{Nb}$ & $\mathrm{Nb}^{93}\left(\mathrm{n}, \mathrm{n}^{\prime}\right) \mathrm{Nb}^{93 \mathrm{~m}}$ & $\mathrm{E}>1.0$ & $16.13 \mathrm{y}$ \\
\cline { 2 - 5 } & $\mathrm{In}$ & $\mathrm{In}^{115}(\mathrm{n}, \gamma) \mathrm{In}^{116 m}$ & $\mathrm{Th}+\mathrm{epi}$ & $54.2 \mathrm{~m}$ \\
& $\mathrm{In}{ }^{115}\left(\mathrm{n}, \mathrm{n}^{\prime}\right) \mathrm{In}^{115 \mathrm{~m}}$ & $\mathrm{E}>1.3$ & $4.486 \mathrm{~h}$ \\
\hline \multirow{2}{*}{ Fission } & $\mathrm{Np}$ & $\mathrm{Np}^{237}(\mathrm{n}, \mathrm{f}) \mathrm{Cs}^{137}$ & $\mathrm{E}>0.6$ & $30.05 \mathrm{y}$ \\
\cline { 2 - 5 } & $\mathrm{U}$ & $\mathrm{U}^{238}(\mathrm{n}, \mathrm{f}) \mathrm{Cs}^{137}$ & $\mathrm{E}>1.5$ & $30.05 \mathrm{y}$ \\
\hline
\end{tabular}

that provide information for nuclear data and validation of calculation schemes. MADERE is accredited by the French Accreditation Committee (COFRAC) for Gamma measurements of standard level specific activity and relative measurements by X-ray spectrometry.

In the last years dosimetry has been applied widely to the reactor mock-ups that have a low flux values. In mock-ups conditions, the activity obtained on the dosimeters is very weak. Due to this MADERE developed procedures and optimised its equipment for performing low level activity Gamma measurements. Gamma measurements are performed by an absolute method. In addition, measurement methods of X-ray emitters have been upgraded in order to allow the use of Rhodium dosimeter. The latter gives access to the intermediate neutron energy spectrum $(0.7 \mathrm{MeV}-1 \mathrm{MeV})$ in the mock-up reactor. While $\mathrm{X}$-ray measurements for $\mathrm{Nb}^{93 \mathrm{~m}}$ are obtained by a relative method, the $\mathrm{X}$-ray measurements for $\mathrm{Rh}^{103 \mathrm{~m}}$ must be performed by an absolute method. The reason is that the reference sample for $\mathrm{Rh}^{103 \mathrm{~m}}$ is not available because of its short decay period (56 minutes). In order to manage an absolute X-ray measurement for $\mathrm{Rh}^{103 \mathrm{~m}}$, MADERE performed some equipment optimisation and improved spectrum treatment and analysis.

\section{MADERE Platform: Dosimeters and Equipment}

MADERE owns seven devices that allow performing activity measurements. All the devices are equipped with GeHP as a detector. Devices differ from each other in efficiency level, shielding, cooling system and GeHP detector geometry. Gamma spectrometry equipment allows measurements of photons with energy from $60 \mathrm{keV}$ to $2 \mathrm{MeV}$. More detailed description of every type of device will be given in Sects. 2.1 through 2.3 .

The dosimeters fabrication has been developed by MADERE in order to ensure better traceability of every dosimeter. There are several types of dosimeters geometry: foils (2-29 $\mathrm{mm}$ in diameter, $0.1-$ $3 \mathrm{~mm}$ in width) and wires $(0.1-1 \mathrm{~mm}$ in diameter) that are used in reactor mock-ups and MTR. Wire dosimeters are encapsulated into quartz bulbs.

Dosimeters, made of ultra-pure material ( $\mathrm{Au}, \mathrm{Ni}, \mathrm{Fe}$ etc.) or of controlled alloy (AlCo), are sensible to a particular energy range of neutrons depending on the isotope. The presence of resonances in the reaction involved in the neutron detection process influences the dosimeter thickness. Commonly used dosimeters that MADERE platform is able to provide are shown in the Table 1. Other dosimeters of V, $\mathrm{Mg}$, Th, Ti etc. can be provided and measured.

All MADERE measurement devices are described below. 


\subsection{Standard Level Activity Gamma Spectrometry (SLAGS) Devices}

MADERE owns 2 devices ("Voie2" and "Passeur") for Gamma measurements of standard level activity. Their relative efficiency is $25 \%$ and the range of activity level goes from $10^{2}$ to $10^{6} \mathrm{~Bq}$ per sample. "Voie2" device can perform measurements in 7 different geometries and "Passeur" in 8 different geometries. Moreover, "Passeur" enables automatic measurement of 40 samples successively. The detector is a coaxial semiconductor GeHP. The preference of GeHP over NaI is justified by the better resolution given by GeHP. For example, in case of $\mathrm{Cs}^{137}$ with peak energy at $661 \mathrm{keV}$, the resolution with $\mathrm{NaI}$ is $40 \mathrm{keV}$ and reduced to $1.3 \mathrm{keV}$ with GeHP. Even if $\mathrm{NaI}$ detectors present a better efficiency level, the resolution in GeHP detectors allows obtaining more detailed spectra and differentiation between very close peaks. Shielding consists of a $5 \mathrm{~cm}$ wide lead wall covered by a thin layer of copper.

In addition to these 2 devices, MADERE owns another equipment ("Voie1"), with a relative efficiency of $10 \%$, used for measurements of activity level slightly stronger than the standard one $\left(10^{3}-10^{7} \mathrm{~Bq}\right)$. "Voie1" is able to perform measurements in 7 different geometries. The shielding, cooling system and detector are identical to the standard level activity devices.

\subsection{Low Level Activity Gamma Spectrometry (LLAGS) Devices}

MADERE benches used for low level activity measurements are called High Efficiency equipment (HE1 and HE2). The High Efficiency devices have 50\% and 60\% relative efficiency levels respectively and the minimal activity that can be measured is about $0.1 \mathrm{~Bq} / \mathrm{sample}$. The detector is a broad energy GeHP (BEGe). The main differences from SLAGS are the detector dimensions, the cooling system and the shielding.

The diameters of LLAGS detectors are two times bigger than the ones of SLAGS. The cooling system still uses nitrogen, but it circulates in a cryostat. Nitrogen evaporates and re-condensates in this cryostat to avoid refilling of nitrogen. This refilling is nevertheless done once every year in order to guarantee the material integrity. The shielding used in LLAGS is $15 \mathrm{~cm}$ wide formed by $13 \mathrm{~cm}$ of lead $(<50 \mathrm{~Bq} / \mathrm{kg}$ ) and $2 \mathrm{~cm}$ of ultra-low background (ULB) lead $0(<25 \mathrm{~Bq} / \mathrm{kg})$. Technological options taken into account for the design of high efficiency measurement devices are described in paragraph 3.

\subsection{X-rays Spectrometry (XS) Devices}

MADERE owns 2 devices (X1 and X2) that can perform X-ray spectrometry measurements. X1 is used for relative measurements of $\mathrm{Nb}^{93 \mathrm{~m}}$ and $\mathrm{X} 2$ is being calibrated in order to perform absolute measurements of $\mathrm{Rh}^{103 \mathrm{~m}}$. The photon energy range that can be measured is $6-300 \mathrm{keV}$ for a low energy GeHP detector (LEGe). Sources available at MADERE allow to establish the efficiency curve between 11.3 and $165 \mathrm{keV}$. The detector has a carbon Epoxy window of $0.6 \mathrm{~mm}$ width that allows the passage of low energy photons. Nevertheless, a careful manipulation is required because of its extreme fragility. The LEGe is cooled by a nitrogen cryostat system. The shielding is $4 \mathrm{~cm}$ wide formed by the same type of lead that is in the SLAGS device. An important element, collimator, has been added to the devices in order to improve the measurement. Both methods, an absolute and a relative one, used for XS are described in Sect. 4.

\section{Low Level Activity: Technological Options Chosen}

The main goal of the LLAGS device is to measure the activity level of about $1 \mathrm{~Bq} / \mathrm{sample}$ dosimeters irradiated in reactor mock-ups. Reaching this objective allows to spread the field of measurement applications. Several specific technological options were chosen in order to manage this goal. 


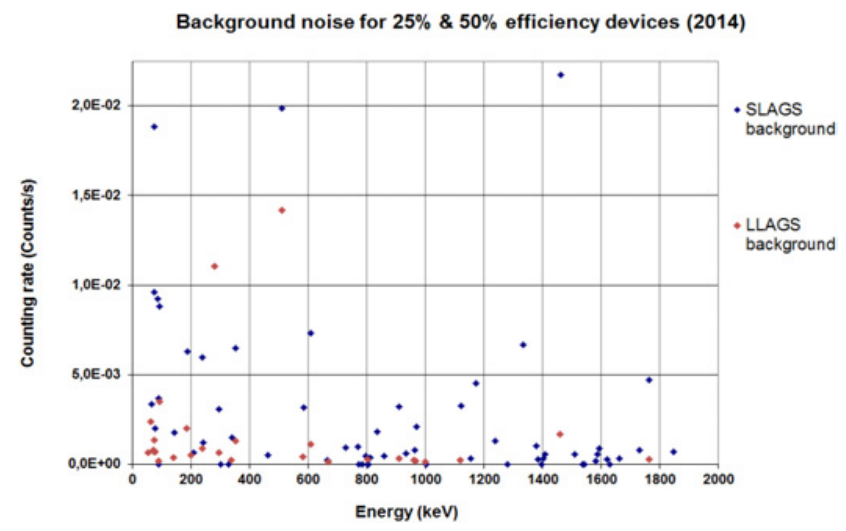

Figure 1. Background noise for $25 \%$ \& $50 \%$ relative efficiency devices (2014).

Problems are mainly encountered during the measurements on low activity samples. The first one is linked with the high efficiency of the measurement device. Since the efficiency is higher (50\%) and the diode is more sensible to the radioactive emission, it is necessary to maintain a low background noise. This is why an ULB lead is used in shielding. This kind of shielding provides lower level of background than the one observed for $25 \%$ efficiency devices (Fig. 1). SLAGS devices present more energy values with the background noise than LLAGS. The decision of selecting this type of lead is based on studies from the Laboratory of Subatomic Physics and Cosmology [1].

The second problem is the time needed to complete the measurement. Since we have to obtain at least 1000 counts/peak, the acquisition time can increase to several weeks. The choice of cryostat cooling system allows performing long duration measurements without cooling reloading during the measurement time. Moreover, in case of an electrical blackout, the detector can be refrigerated by the liquid nitrogen for a period of 6 days, thereby allowing a continuous measurement and giving a time delay for establishing the normal electrical supply.

The last problem concerns the distance between the sample and the diode. In order to spend less time measuring we should place the sample as close as possible to the diode. This approach means increasing solid angle and explains the need of bigger diameter of detector in LLAGS than in SLAGS. The Gamma-Gamma coincidence event becomes more important when the sample is too close to the diode. In order to take this phenomenon into account the software ETNA [2], developed by the French primary Henri Becquerel National Laboratory (LNHB), is used to perform a simulation and the effect calculated by ETNA is applied to the final measurement. This correction factor depends on the distance to the diode and the disintegration schema. The biggest $\gamma-\gamma$ coincidence correction is obtained for $\mathrm{Ag}^{110 \mathrm{~m}}$ and is about $30 \%$. ETNA software provides reliable corrections and the effect of $\gamma-\gamma$ coincidence is now well studied.

LLAGS device has allowed to perform a non-destructive $\gamma$ measurement on a miniature fission chamber in order to determine the ratio $\mathrm{U}^{235} / \mathrm{U}^{238}$ [3]. The difficulty is that the mass of the fission covering in the chamber is less that $1 \mathrm{mg}$ and its activity is about $10^{-3}$ counts/s. Moreover, the chemical analyse is not possible because it would destroy the fission chamber itself. The measurement of $2 \gamma$ peaks during several weeks was successfully performed and gave a final result with the uncertainty of $5 \%$ for the ratio $\mathrm{U}^{235} / \mathrm{U}^{238}>1000 \mathrm{ppm}$. The determination of this ratio into the fission chamber is crucial since it plays an important role on the background noise into the measurement of the fast neutron flux in the reactor. 


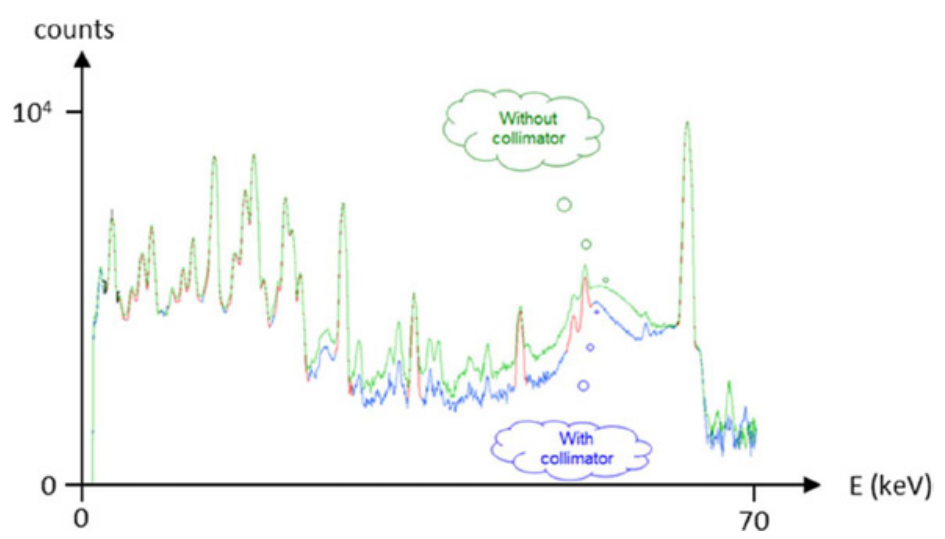

Figure 2. The device output, $\mathrm{Am}^{241}$ spectrum with and without one collimator element [4].

\section{X-rays Spectrometry: Measurement Methods and Optimization}

This section begins by the description of a collimator that can be used in comparative and in absolute measurement. Afterwards, both methods are explained. It is interesting to note that MADERE is dimensioned for measurements on solid metal samples even if the radiochemistry measurement is commonly used by other laboratories. The reason for measuring directly the solid sample is that, in the context of reactor dosimetry, the laboratory is not allowed to destroy the dosimeter and the solid sample must be available after the X-ray measurement. Concerning the absolute method, it was developed in order to be able to measure Rhodium samples since the information given by this isotope provides data for the neutron flux in the energy range near $1 \mathrm{MeV}$.

A lot of physical phenomena take place in a GeHP detector. Some of them produce a perturbation effect on the measurements. The most important perturbation is due to the Compton diffusion. During the Compton diffusion, X-rays change their direction and lose part of their energy leading to the recording of peaks whose energy is lower than the total absorption peak. This event makes it difficult to treat the total absorption peak in order to calculate its area (that is linked to the activity of the sample). In order to reduce this parasite contribution to a minimum, a collimator element was added.

The collimator, made of tantalum (Ta), has disc geometry and is placed between the sample and the detector window. Diffused X-rays are stopped by the collimator and a more proper X-ray spectrum is obtained. First studies in 2007 [4] were performed with one collimator. Spectra with and without a collimator are presented in Fig. 2. The collimator fixing system is made of Plexiglas, which is a light material, in order to favor the X-ray crossing and not its diffusion. The first drawback of the collimator is that the amount of X-rays reaching the detector is low thereby necessitating long-time acquisitions. This drawback is partially solved by the cryostat system since the measurement is not stopped in order to refill the cooling circuit with nitrogen. The second drawback is the appearance of two additional peaks due to the presence of Ta, having $56.3 \mathrm{keV}$ and $57.5 \mathrm{keV}$ energies. In this case, the high resolution device allows the discrimination of the two Ta peaks from other peaks close to them. This second drawback is completely understood and solved after the first studies.

A second collimator has been added for further measurements related to a up-coming CEA experimental program. A 2013 study suggests that adding the second collimator as close as possible to the detector window and another one, closer to the sample, improves the spectrum with less Compton perturbation than with only one collimator.

In order to measure $\mathrm{Nb}^{93 \mathrm{~m}}$ samples MADERE performs a comparative measurement using a reference sample whose activity is certified by the French primary laboratory for activity measurements 


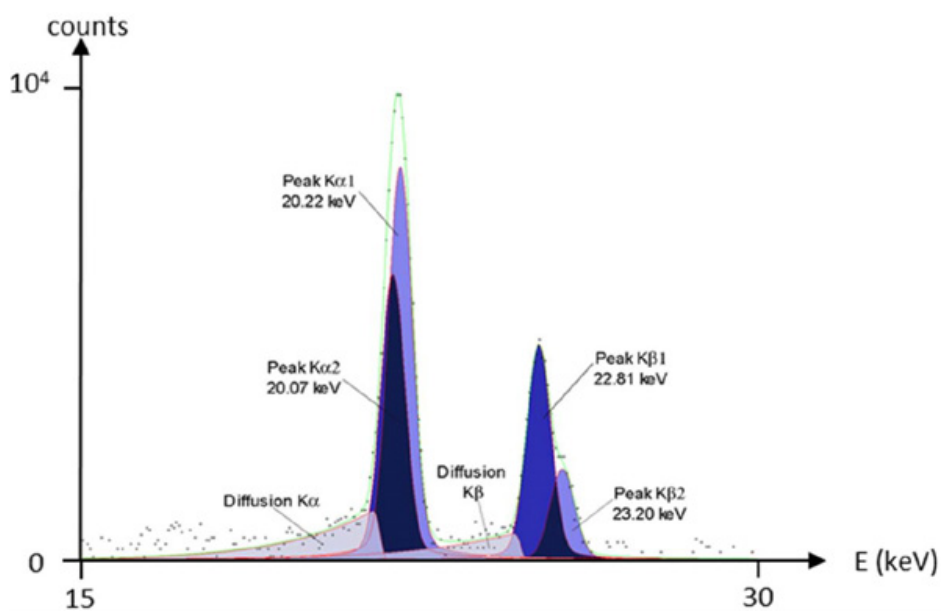

Figure 3. The COLEGRAM fitting output for $\mathrm{Rh}^{103 \mathrm{~m}}$ spectrum from a 2007 study [4].

(LNHB). This way of measuring is called a relative method. The main advantage is that the selfabsorption effect of X-ray in the sample can be simplified between the sample and the reference. The only constraint is that measurements should be done in exactly the same geometry conditions of the reference measurement. The measured sample has to be positioned at the solid angle $\Omega \leq \Omega_{\text {ref }}$, where $\Omega_{\mathrm{ref}}$ is the position for reference characterization. If the sample has to be measured closer to the detector $\left(\Omega>\Omega_{\text {ref }}\right.$ ) it is necessary to perform a new reference characterization in geometrical condition of a new $\Omega_{\text {ref }}^{*}>\Omega_{\text {ref. }}$. MADERE Nb ${ }^{93 \mathrm{~m}}$ reference is characterized for two different solid angles. The relative method is now performed with better knowledge of physical phenomena. Experience acquired for this method leads to more satisfactory results.

For $\mathrm{Rh}^{103 \mathrm{~m}}$ samples MADERE performs an absolute measurement. During the 2007 study [4] the device was calibrated using reference sources with energies between 11.3 and $60 \mathrm{keV}$ since $\mathrm{Rh}^{103 \mathrm{~m}}$ has its most probable X emission at the energies of $20.17 \mathrm{keV}$ and $22.87 \mathrm{keV}$. Sources used were $\mathrm{Am}^{241}$, $\mathrm{Cd}^{109}$ and $\mathrm{Nb}^{93 \mathrm{~m}} \cdot \mathrm{Cs}^{137}$ and $\mathrm{Co}^{57}$ sources were used in order to check the obtained curve. The present efficiency curve is determined using 8 reference sources, $\mathrm{Am}^{241}, \mathrm{Cd}^{109}, \mathrm{Nb}^{93 m}, \mathrm{Ce}^{139}, \mathrm{Co}^{57}, \mathrm{Cs}^{137}, \mathrm{Sn}^{113}$ and $\mathrm{Ba}^{133}$ which allow spreading the energy range from $11 \mathrm{kev}$ to $165 \mathrm{keV}$ instead of $60 \mathrm{keV}$ as in 2007 .

Due to the origins of X-rays (electronic cortex and not a nucleus as for the Gamma photons) the peak form is a Voigt curve. The electronic system GENIE2000 (CANBERRA), developed to deal with Gaussian Gamma peaks can't treat X-ray peaks from an absolute measure. The software called COLEGRAM [5], developed by LNHB, was first used in 2007 in order to fit the experimental measured curves to the analytic functions (Fig. 3) and deduce peaks emerging from the spectrum. The same COLEGRAM procedure is used for the current X-ray measurements.

Correction coefficients have to be taken into account in order to create the total absorption efficiency curve. The main coefficients are detailed in the next part of this article. Uncertainties are also calculated.

\section{Correction Factors and Uncertainties}

Correction factors should be applied during the efficiency curve calibration and also during the sample measurement.

$$
F(E)=\frac{S(E)}{E f f^{P}(E) * t} * C_{r} * C_{g} * C_{c} * C_{(\text {auto-abs })} * C_{\text {abs }} * C_{f} * C_{\Omega}
$$




$$
\mathrm{A}=\frac{\mathrm{F}(\mathrm{E})}{\mathrm{I}(\mathrm{E})} .
$$

Equation (1) is used to calibrate the efficiency curves with the reference sources and to determine sample activities. Applied parameters are: "Eff $\mathrm{P}(\mathrm{E})$ " for efficiency, "S(E)" for the surface under the peak of total absorption, " $F(E)$ " for the flux of photons and " $t$ " for the counting time (s). The flux of photons and the sample activity are related in Eq. (2) where $F(E)$ is the photons flux at the peak of energy $E$ and $I(E)$ is the emission intensity of the peak $\mathrm{E}$.

$\mathrm{C}_{\mathrm{r}}$ is necessary for taking into account the sample/source decay between the end of irradiation and the start of the measurement (cooling time). Since the activity law is $\mathrm{A}(\mathrm{t})=\lambda \mathrm{N}_{0} * \mathrm{e}^{-\lambda t}$ and the activity value at the end of irradiation is needed, we have

$$
C_{r}=e^{-\lambda\left(t_{m}-t_{0}\right)} .
$$

Where $\left(t_{m}-t_{0}\right)$ is the time passed between the end of irradiation and the beginning of the measurement, $\lambda$ is the radioactive decay constant of the sample.

$\mathrm{C}_{\mathrm{g}}$ is needed to correct the sample position considering the distance between the point of photon emission and the detector window. This correction is made by converting the real distance to the reference distance.

$\mathrm{C}_{\mathrm{c}}$ helps to adjust the effect of photons emitted in cascade.

$\mathrm{C}_{\mathrm{f}}$ helps to correct activity measurements when natural disintegration of the sample is significant during acquisition $\left(\mathrm{C}_{\mathrm{f}}=1\right.$ when calibrating the efficiency curve).

$\mathrm{C}_{\Omega}$ allows to account for the difference in terms of emission ways between the sample and sources (surface emission vs. punctual emission) $\mathrm{C}_{\Omega}=1$ in case of efficiency calibration with sources.

$\mathrm{C}_{\mathrm{abs}}$ is used while dealing with photons flux and not the sample activity. This factor takes into account the photons absorption that can happen inside the material (PET) that covers the source.

$\mathrm{C}_{\text {(auto-abs) }}$ is used to take into account the self-absorption in the sample depending on its width, meanwhile the source width is considered non-significant $\left(\mathrm{C}_{(\text {auto-abs })}=1\right)$. This correction factor is applied in case of absolute measurement. The lower the energy of the measured photon, the higher this correction. Low energy increases the possibility of the total absorption of the emitted photon inside the sample without leaving it. This important event is called "self-absorption". Correction due to this factor is about $40 \%$ for $\mathrm{Rh}^{103 m}$ samples. The obvious solution to this problem is to measure a very thin sample, but the low activity level should be considered. Since the lack of activity for the measurement is partially solved by increasing the mass of the sample, equilibrium should be reached between a weak selfabsorption and enough specific activity. $\mathrm{C}_{(\text {auto-abs) }}$ depends on the attenuation coefficient for the sample element. $\mathrm{Rh}^{103 \mathrm{~m}}$ attenuation coefficients were calculated by both experiments and MCNP simulations for increasing samples widths [4]. The first available data on self-absorption coefficients were taken from NIST XCOM and NIST X-Ray database [6]. Experimental validation on SOLEX (Source Of Low Energy X-rays) facility was performed for $\mathrm{Nb}^{93 \mathrm{~m}}, \mathrm{Rh}^{103 \mathrm{~m}}$ and mylar. The results proved that the values for $\mathrm{Nb}^{93 \mathrm{~m}}$ and $\mathrm{Rh}^{103 \mathrm{~m}}$ from XCOM shouldn't be used for the interpolation. X-Ray database is more coherent with experimental values obtained in SOLEX. This study also validates the procedure of selfabsorption calculation in MADERE.

Uncertainties are calculated for all efficiency values during the calibration and for the final sample activity. The total uncertainty is the sum of the partial ones considering that they are independent. The general law of uncertainties calculated for $y=f(x)$ is:

$$
U_{t o t}^{2}(y)=\sum_{k=1}^{n}\left(\frac{\partial f}{\partial x_{k}}\right)^{2} U^{2}\left(x_{k}\right) .
$$

The total uncertainty for the efficiency value is a sum of an absolute uncertainty of the peak surface, absolute uncertainty due to the fitting by COLEGRAM or GENIE2000 (in case of X-ray or $\gamma$ measurements), absolute uncertainty on the photons flux of the source, absolute uncertainty due to every 
Table 2. Extension of the MADERE scope.

\begin{tabular}{|c|c|c|}
\hline & Before 2008 (2012 for X-ray) & After 2008 (2012 for X-ray) \\
\hline $\begin{array}{l}\gamma \text { measurement on } \\
\text { solid samples }\end{array}$ & $\mathrm{A}>$ few Bq (cf. Table 1) & $\begin{array}{c}\text { Isotopes from Table } 1+\text { new } \\
\text { dosimeters of: } \mathrm{V} \text { (measurement of } \\
\left.\mathrm{Sc}^{46} \text { ), Ti (measurement of } \mathrm{Sc}^{48}\right), \mathrm{Al} \\
\text { (measurement of } \mathrm{Na}^{24} \text { ) with } \\
\text { experimental uncertainty of } 3 \%, 2 \% \\
\text { and } 1.5 \% \text { respectively }\end{array}$ \\
\hline $\begin{array}{l}\text { X-ray measurement } \\
\text { on solid samples }\end{array}$ & $\begin{array}{l}\text { Relative method limited only to } \\
\text { isotopes with long half-lives such } \\
\text { as } \mathrm{Nb}^{93 \mathrm{~m}} \text { and specific geometry of } \\
\text { a sample. Minimum energy } \\
\text { measured is } 60 \mathrm{keV}\end{array}$ & $\begin{array}{c}\text { Absolute method developed, more } \\
\text { liberty in the geometry of the } \\
\text { samples, the range of energy is } \\
\text { increased until } 11 \mathrm{keV} \text { (and till } 165 \mathrm{keV} \text { ) } \\
\text { that allows future applications } \\
\text { to the new isotopes }\end{array}$ \\
\hline
\end{tabular}

correction factor. This uncertainty sum-up is calculated during the calibration of efficiency curve and also during the activity measurements of the sample in order to calculate the outgoing flux of photons.

When it is necessary to give the activity value, the Eq. (2) is used for the passage from the photon flux to the activity. In this case, the total uncertainty for the activity value is affected, in addition to the uncertainties exposed above, by the uncertainty on the emission intensity of the considered peak. For example, the relative uncertainty of the emission intensity for $\mathrm{Rh}^{103 \mathrm{~m}}(4.6 \%)$ affects strongly the final value of activity uncertainty which is about $5 \%(\mathrm{k}=1)$.

Besides uncertainty diminution on the photon flux, achieved by improving the determination of attenuation coefficients, improvements on nuclear data will help to reduce the activity uncertainties.

\section{Conclusions}

MADERE platform allows certified (COFRAC) measurements of standard $\gamma$ activity, low $\gamma$ activity and $\mathrm{X}$-rays activity of $\mathrm{Nb}^{93 \mathrm{~m}}$. It is planned to validate definitely the measurement procedure for $\mathrm{Nb}^{93 \mathrm{~m}}$ by comparing the results obtained by radiochemistry (dissolving the sample) and MADERE absolute measurement on a solid sample.

The recent improvements presented in this paper help to spread the field of possibility for measurements in energy and activities. Concerning X-rays measurement, it is now also possible to perform absolute measurements on $\mathrm{Rh}^{103 \mathrm{~m}}$. Thanks to the new devices, very low activate samples will be measured from the up-coming experimental program. In the future, the aim is to become certified by COFRAC also in absolute X-ray measurements. Moreover, the progress made in the measurement techniques makes possible the development of new type of dosimeters ( $\mathrm{X}$ emitters, low sensibility or low probability emission) possible. The sum-up of the global evolution is presented with the Table 2 .

In addition, simulation tools for diminishing the time spent on calibration of the efficiency curve are under investigation: a comparison between an industrial simulation code [7] and the modelling of the detection system under development using TRIPOLI-4 [8] code (based on Monte Carlo simulation).

Finally, in order to diminish the final activity uncertainties, nuclear data improvement is studied in partnership with LNHB (attenuation coefficients, intensities of emission etc.)

\section{References}

[1] http://lpsc.in2p3.fr/index.php/fr/valorisation/domaines-de-valorisation/ lba/65-valorisation/lba/404-le-lba-en-detail

[2] M.C. Lépy, M.M. Bé, F. Piton, ETNA (Efficiency Transfer for Nuclide Activity measurements) Logiciel pour le calcul du transfert de rendement et des corrections de coïncidences en spectrométrie gamma, Note Technique CEA/LNHB/01/09/F 


$$
15^{\text {th }} \text { ISRD }
$$

[3] Patent $\mathrm{N}^{\circ}$ EP2010064220 Procédé de détermination du rapport isotopique de matière fissile contenue dans une chambre a fission. C. Vaglio-Gaudard, J.M. Girard, P. Leconte

[4] C. Domergue, Mesure d'activité d'échantillons de $\mathrm{Rh}^{103 \mathrm{~m}}$ émetteur $\mathrm{X}$ irradiés en réacteur : application au programme FLUOLE réalisé dans EOLE, mémoire C.N.A.M (2007)

[5] M.C. Lépy, Presentation of the COLEGRAM software, NT_04-26 CEA/LNHB

[6] http://www.nist.gov/pml/data/

[7] http://www.canberra.com/fr/produits

[8] TRIPOLI-4® Project Team, Overview of TRIPOLI-4 version 7 Continuous-energy Monte Carlo Transport Code, ICAPP 2011, May 2nd-5th, Nice, France 